\title{
Explaining the effects of a point-of-purchase nutrition-information intervention in university canteens: a structural equation modelling analysis
}

\author{
Christine Hoefkens ${ }^{1,2^{*}}$, Zuzanna Pieniak², John Van Camp ${ }^{1}$ and Wim Verbeke ${ }^{2}$
}

\begin{abstract}
Background: The importance of canteen meals in the diet of many university students makes the provision of simple point-of-purchase (POP) nutrition information in university canteens a potentially effective way to promote healthier diets in an important group of young adults. However, modifications to environments such as the posting of POP nutrition information in canteens may not cause an immediate change in meal choices and nutrient intakes. The present study aimed at understanding the process by which the POP nutrition information achieved its effects on the meal choice and energy intake, and whether the information was more effective in changing the meal choice of subgroups of university canteen customers.

Methods: The POP nutrition-information intervention used a one-group pretest-posttest design. A sample of 224 customers of two university canteens completed the baseline and 6-months follow-up surveys. A multi-group structural equation modelling analysis was used to test mediation effects of individual difference variables (liking, understanding and use of the information, subjective knowledge and attitude) on the energy intake from canteen meals, moderated by the objective nutrition knowledge and motivation to change diet.
\end{abstract}

Results: Significant relations were identified between liking of the information and its use on one hand and a positive effect in attitude towards healthy canteen meals on the other hand. Motivation to change diet and sufficient objective nutrition knowledge were required to maintain a recommended energy intake from canteen meals or to lead to a decrease in energy intake. Participants with greater objective nutrition knowledge had a greater understanding of the POP nutrition information which also resulted in a more effective use of the information.

Conclusions: The results suggest that nutrition-information interventions may be more effective when using nutrition information that is generally liked by the target population in combination with an educational intervention to increase objective nutrition knowledge.

Trial registration: NCT01249508

Keywords: Point-of-purchase information, University canteen meals, Young adults, Information processing, Motivation, Nutrition knowledge, Moderated mediation model, Structural equation modelling

\footnotetext{
* Correspondence: Christine.Hoefkens@UGent.be

'Department of Food Safety and Food Quality, Ghent University, Faculty of Bioscience Engineering, Coupure Links 653 B-9000, Ghent, Belgium

${ }^{2}$ Department of Agricultural Economics, Ghent University, Faculty of

Bioscience Engineering, Coupure Links 653 B-9000, Ghent, Belgium
} 


\section{Background}

Young adults often establish unfavourable dietary habits when leaving the parental home to enter university, i.e. consuming a diet of limited variety, high snacking, consuming more high-fat foods (including fast foods), more soft drinks, and less fruit and vegetables [1-3]. Such habits may have a long-lasting impact on their own health or the health of their future families [3,4]. Therefore, it is important to promote maintenance of adequate nutritional habits learned at home or to improve current eating habits.

For many university students canteen meals constitute an important part of the diet [5]. Because canteen customers might not be aware of the nutritional quality of their meal choices [6], which are often too rich in energy, fat and sodium, and contain insufficient amounts of fruit and vegetables $[7,8]$, dietary guidance through simplified point-of-purchase (POP) nutrition information on menu choices in canteens could be a strategically important approach to promote healthy dietary choices.

Evaluation of the overall effect of a POP nutritioninformation intervention in two canteens of Ghent University showed that nutrition information by using a star-rating system as signage did not effectively change meal choices and nutrient intakes [9]. Modifications to the environment such as posting nutrition information in university canteens might not cause an immediate dietary change [10]. Consumer behaviour and information processing models posit that communication and information efforts, if being attended to and properly processed, move individuals through a sequence of hierarchical stages, often referred to as a "hierarchy of effects" [11,12]. This concept indicates the different mental stages that consumers go through after being exposed to information and when responding to information and making buying decisions. While it is generally accepted that a structure includes a cognitive response (learning, knowing), an affective response relating to attitude formation (thinking, feeling) and (ultimately) a behavioural response (intending, doing), the sequence and separation of these hierarchical steps depend on person-related, product-related and situational factors. In this study, the classical sequence from knowledge to behaviour was assumed [13,14]. Furthermore, direct paths from each step of the hierarchy to the behavioural stage were investigated.

In addition, the effect of nutrition information on dietary behaviour may differ between individuals $[15,16]$. To examine causal pathways of information effects in subgroups of canteen customers, moderated mediation models are especially valuable. In these statistical models, a third variable mediates the effect of an independent variable on the dependent variable, and this mediated or indirect effect depends on the level of a moderator (i.e. conditional indirect effect) [17]. Despite the acknowledged importance of investigating mediation and moderation effects of interventions on dietary behaviour, only a few studies have done so and none of them have evaluated a nutrition-information intervention in a canteen environment $[18,19]$.

The objective of the study was to explain the ineffectiveness of our nutrition-information intervention in university canteens [9]. A moderated mediation model was estimated to examine, first, the process by which the POP nutrition information achieved its effects on the meal choice and energy intake, and second, whether the information was more effective in changing the meal choice of subgroups of university canteen customers. From consumer behaviour models, our first hypothesis was that individuals who understand and like the POP nutrition information, will be more likely to use the information, will increase their subjective knowledge about how to evaluate the healthiness of a food, leading to a more positive attitude towards healthy canteen meals and ultimately to a healthier meal choice (Figure 1). A second hypothesis was that the POP nutrition information would be most effective among more motivated and more knowledgeable individuals [16]. Because the information was designed to facilitate the identification of healthier meal choices, also less knowledgeable consumers with a high motivation to change their diet were hypothesized to be positively influenced by the intervention.

\section{Methods}

\section{Study design and participants}

The nutrition-information intervention that forms the starting point of the present study used a one-group pretest-posttest design. A convenience sample of 224 students ( 165 females and 59 males) between the ages of 17 and 35 years (Mean 21 years, SD 3), who were regular customers of two canteens of Ghent university (Belgium), enrolled in the intervention (59\% of the baseline sample) and completed three-day food records and self-administered structured questionnaires at baseline (October and November 2008) and follow-up (April and May 2009).

Customers of the canteens of Ghent University compose their meal by choosing one protein component, one sauce component, one vegetable component and a carbohydrate source. As such, about 180 meal combinations are possibly chosen and consumed daily. Because of display place constraints and the risk of information overload, each day a selection of 12 meals (ie, the three best meal options for each of the four protein components) was communicated. These 12 best meal combinations were selected based on the compliance of a meal's content of energy, saturated fat, sodium, and the size of the vegetable portion with the respective meal 


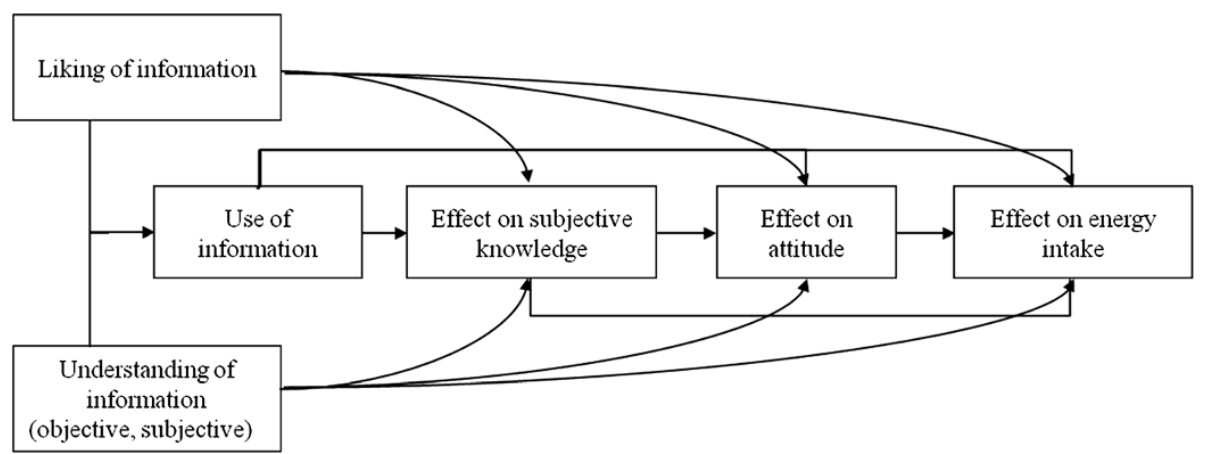

Figure 1 Hypothetical model of the process by which the nutrition information achieves its effects on the meal choice and energy intake.

recommendations (for energy: $<500 \mathrm{kcal}$, saturated fat: $<13 \%$ of energy, sodium: $<2.2 \mathrm{mg} / \mathrm{kcal}$, and vegetable: $>150$ g [20-22]).

The nutrition information on the best meal combinations, which was first posted in March 2009, consisted of a star rating ranging from zero to three stars and a descriptor for nutrients or food group that did not comply with recommendations. If a meal complied with a recommendation, it received a score of 1 . The maximum score was 4 , which would mean that the meal complied with the meal recommendation for energy, saturated fat, sodium and the amount of vegetables. These scores were translated into stars, whereby scores 2,3 , and 4 received, respectively, 1, 2, and 3 stars. Participants were not informed about the posting of nutrition information in the university canteens but only about the study purpose of assessing eating habits. They were explained that measurements at two points in time were necessary to have a proper representation of consumption patterns. Other measures taken to reduce possible bias from experimenter demand effects, were the posting of the labels in the canteens before opening hours and the formatting of supportive material according to the house style of all communications by the canteen administration. As such, the posted nutrition information and other materials did not contain any link to the study or researchers. A more detailed description of the nutrition-information intervention, the sample characteristics and results of the overall efficacy of the intervention are provided in Hoefkens et al. [9]. The study protocol was granted ethics approval by the Belgian Ethics Committee of the Ghent University Hospital (ethics approval number EC/2008/482) and registered on ClinicalTrials.gov (Id number NCT01249508).

\section{Measures}

\section{Behavioural outcome}

The primary outcome variable of the intervention was the number of chosen meals that complied with all recommendations (i.e. three-star meals) [9]. The present study used the energy intake from the canteen meal as a proxy for the star rating of the reported meal choice. The energy intake from the canteen meal at both baseline and follow-up were calculated as the average of the three days collected through self-administered food records together with the energy values and standardized portion sizes of the meal components provided by the caterer. Based on the difference in energy intake from the canteen meal between follow-up and baseline, participants were categorized into (1) increasing energy intake (i.e. increase of more than one standard deviation with $\mathrm{SD}=147 \mathrm{kcal}$ ), (2) maintaining high energy intake, (3) maintaining moderate energy intake, (4) maintaining low or recommended energy intake, and (5) decreasing energy intake (i.e. decrease of more than $147 \mathrm{kcal}$ ). The mean (SD) and the distribution of the outcome variable are presented in Table 1.

\section{Theory-based mediators}

The theoretical framework of the nutrition-information intervention was based on a combination of the model of consumer information processing proposed by Grunert and Wills [23] and the Hierarchy-of-effects (HOE) model [11].

The hypothesized mediators related to information processing were liking of the information (3 items; Cronbach's alpha $=0.81)[24,25]$, subjective understanding (3 items; Cronbach's alpha $=0.80)$ [26], objective understanding (aggregated score on 14 items; see further) and self-reported use of the information (5 items; Cronbach's alpha $=0.93$ ) [27] (Table 1). Liking was measured on a 7-point interval scale from "totally not" to "very much" using the items:"I like the information", "The information is attractive to me", "The information is interesting to me". Subjective understanding of the information was measured on a 7-point Likert scale (from "totally disagree" to "totally agree") using a 3-item measure including "The information is hard to interpret/ 
Table 1 Descriptive characteristics (mean \pm SD, frequency (\%)) for the total sample and subgroups

\begin{tabular}{|c|c|c|c|c|c|}
\hline & & & $\begin{array}{l}\text { Total sample } \\
(\mathrm{n}=220)^{\mathrm{a}}\end{array}$ & $\begin{array}{l}\text { People with } \\
\text { low knowledge } \\
\text { and high intention } \\
(n=70)\end{array}$ & $\begin{array}{l}\text { People with } \\
\text { high knowledge } \\
\text { and high intention } \\
(n=44)\end{array}$ \\
\hline \multirow[t]{43}{*}{ Mediator } & Effect on energy intake & Mean $\pm S D$ & $1.10 \pm 147$ & $-27.88 \pm 132$ & $-30.66 \pm 126$ \\
\hline & Increase in energy intake & Frequency (\%) & 5 & 9 & 5 \\
\hline & Maintenance of high energy intake & & 17 & 10 & 18 \\
\hline & Maintenance of moderate energy intake & & 55 & 57 & 59 \\
\hline & Maintenance of low or recommended energy intake & & 16 & 16 & 11 \\
\hline & Decrease in energy intake & & 6 & 9 & 7 \\
\hline & Effect on attitude & Mean \pm SD & $-0.69 \pm 1.34$ & $-0.61 \pm 1.15$ & $-0.64 \pm 1.35$ \\
\hline & Negative change in attitude & Frequency (\%) & 10 & 7 & 2 \\
\hline & Maintenance of low attitude & & 23 & 19 & 25 \\
\hline & Maintenance of moderate attitude & & 34 & 40 & 32 \\
\hline & Maintenance of high attitude & & 5 & 4 & 7 \\
\hline & Positive change in attitude & & 27 & 30 & 34 \\
\hline & Effect on subjective knowledge & Mean \pm SD & $-0.05 \pm 0.94$ & $-0.12 \pm 0.99$ & $-0.07 \pm 0.71$ \\
\hline & Negative change in knowledge & Frequency (\%) & 10 & 11 & 11 \\
\hline & Maintenance of low knowledge & & 11 & 13 & 9 \\
\hline & Maintenance of moderate knowledge & & 23 & 30 & 14 \\
\hline & Maintenance of high knowledge & & 8 & 6 & 5 \\
\hline & Positive change in knowledge & & 49 & 40 & 61 \\
\hline & Use of information ${ }^{\mathbf{b}}$ & Mean \pm SD & $2.90 \pm 1.51$ & $3.03 \pm 1.47$ & $3.21 \pm 1.52$ \\
\hline & Never & Frequency (\%) & 27 & 24 & 23 \\
\hline & Rarely & & 20 & 16 & 14 \\
\hline & Occasionally & & 15 & 17 & 14 \\
\hline & Sometimes & & 24 & 27 & 30 \\
\hline & Regularly & & 10 & 13 & 16 \\
\hline & Often & & 4 & 1 & 5 \\
\hline & Always & & 1 & 1 & 0 \\
\hline & Subjective understanding of information ${ }^{b}$ & Mean \pm SD & $4.54 \pm 1.25$ & $4.54 \pm 1.23$ & $4.45 \pm 1.17$ \\
\hline & Totally disagree & Frequency (\%) & 2 & 1 & 0 \\
\hline & Disagree & & 5 & 3 & 5 \\
\hline & Rather disagree & & 11 & 13 & 16 \\
\hline & Neither agree, nor disagree & & 30 & 33 & 34 \\
\hline & Rather agree & & 26 & 27 & 25 \\
\hline & Agree & & 22 & 17 & 18 \\
\hline & Totally agree & & 4 & 6 & 2 \\
\hline & Objective understanding of information & Mean \pm SD & $10.19 \pm 2.25$ & $9.63 \pm 2.29$ & $10.32 \pm 1.91$ \\
\hline & Liking of information ${ }^{b}$ & Mean \pm SD & $4.35 \pm 1.06$ & $4.43 \pm 1.02$ & $4.56 \pm 1.00$ \\
\hline & Not like at all & Frequency (\%) & 2 & 3 & 0 \\
\hline & Moderately dislike & & 3 & 1 & 5 \\
\hline & Slightly dislike & & 12 & 9 & 5 \\
\hline & Neutral & & 34 & 34 & 34 \\
\hline & Slightly like & & 39 & 41 & 39 \\
\hline & Moderately like & & 11 & 11 & 18 \\
\hline & Like very much & & 0 & 0 & 0 \\
\hline
\end{tabular}


Table 1 Descriptive characteristics (mean \pm SD, frequency $(\%)$ ) for the total sample and subgroups (Continued)

\begin{tabular}{|c|c|c|c|c|c|}
\hline \multirow[t]{9}{*}{ Moderator } & Objective nutrition knowledge & Mean $\pm S D$ & $9.10 \pm 1.53$ & $7.03 \pm 1.65$ & $11.92 \pm 1.76$ \\
\hline & Intention to change $\operatorname{diet}^{\mathrm{b}}$ & Mean $\pm S D$ & $4.65 \pm 1.16$ & $5.53 \pm 0.63$ & $5.44 \pm 0.58$ \\
\hline & Very unlikely & Frequency (\%) & 2 & 0 & 0 \\
\hline & Unlikely & & 3 & 0 & 0 \\
\hline & Rather unlikely & & 9 & 0 & 0 \\
\hline & Neutral & & 29 & 0 & 0 \\
\hline & Rather likely & & 35 & 54 & 59 \\
\hline & Likely & & 18 & 37 & 34 \\
\hline & Very likely & & 4 & 9 & 7 \\
\hline
\end{tabular}

${ }^{a}$ Four individuals were removed from the sample because of incomplete information, leaving a final sample of 220 valid cases.

b Distributional labels for the response categories " 2 ", " 3 ", " 5 "," 6 " were not present on the scales at data collection, but are included in the table for clarity of presentation.

hard to extract/difficult to understand". For objective understanding, an index was computed counting the number of correct answers to 14 multiple-choice questions on the definition and the interpretation of the starrating information (scores from 0 to 14). To assess usage of the information, participants were asked to rate on a 7-point scale how often (ranging from "never" to "always") they used the information (1) to make their meal choice, (2) to choose the healthiest meal, (3) to avoid meals containing too much energy, (4) to avoid meals containing too much saturated fat, (5) to avoid meals containing too much sodium (salt).

Two potential mediators derived from the HOE model were "effect on subjective knowledge" about the healthiness of a food and "effect on attitude" towards healthy canteen meals (Table 1). Subjective knowledge (4 items; Cronbach's alpha: baseline $=0.75$, follow-up $=0.81$ ) $[28]$ and attitude (single item) [29] were measured at baseline and follow-up by asking participants' agreement with a series of questions on a 7-point Likert scale. Examples of items used to measure subjective knowledge are "I have a lot of knowledge about how to evaluate the nutritional value of a food", "I have a lot of knowledge about how to prepare a healthy meal", "I know which food is healthy for me" and "My friends consider me as an expert in healthy foods". Attitude was measured using the following item "Canteen meals that are designated as healthy choices are better for me". For the effect on subjective knowledge a score of one to five was assigned as follows: (1) negative change in knowledge, (2) maintaining low knowledge, (3) maintaining moderate knowledge, (4) maintaining high knowledge, (5) positive change in knowledge. The same classification procedure was used to derive effect on attitude with five final categories: (1) negative change in attitude, (2) maintaining low attitude, (3) maintaining moderate attitude, (4) maintaining high attitude, (5) positive change in attitude. A decrease and increase in knowledge or attitude from baseline to follow-up of more than one standard deviation (with $\mathrm{SD}=0.94$ for change in subjective knowledge; $\mathrm{SD}=1.34$ for effect on attitude) on a 7-point scale was used to classify participants under categories 1 and 5 , respectively.

Both single and multiple items were used to measure mediator constructs. Multiple items are often preferred above a single item in order to capture more of the construct meaning and to enhance construct validity $[30,31]$. However, recent research has indicated that the predictive validity of single-item measures for concrete constructs are as predictive as multi-item measures [32]. Regarding the number of items to be considered, no concrete rule of thumb exists.

\section{Theory-based moderators}

The potential moderators of the intervention effects were defined on the basis of the objective nutrition knowledge and intention to change diet at baseline. Four subgroups of individuals were compared: those with (1) high knowledge and high intention $(\mathrm{n}=44)$, (2) high knowledge and low intention $(\mathrm{n}=54)$, (3) low knowledge and high intention $(\mathrm{n}=70)$, (4) low knowledge and low intention $(n=52)$. Objective nutrition knowledge was determined using the index of knowledge on dietary recommendations developed by Grunert et al. [33]. High versus low knowledge was defined as a score of more versus less than 8.5 on 19 items. Participants' intention to change their diet in the next six months (used as a proxy for motivation to change diet) was measured on a 7-point interval scale from "very unlikely" to "very likely" (5 items; Cronbach's alpha $=0.94$ ) by means of the following items: "I plan/expect/desire/intend/want to eat more healthy" [34]. A median split (cut-off $=4.7$ ) was used to form high and low subgroups on intention of dietary change. The mean (SD) and the distribution of the moderators for the different subgroups are presented in Table 1.

\section{Statistical analyses}

Data were analyzed using the robust maximum likelihood procedure in LISREL 8.72 [35]. First, a structural 
equation modelling (SEM) analysis was used to test the hypothesized model (Figure 1) for the total sample. Second, a multi-group SEM analysis was performed to investigate the same model in the four subgroups of individuals (characterized by moderating factors) and, as such, to provide insights in differences in the effectiveness of the intervention between the subgroups. SEM is a multivariate technique combining aspects of factor analysis and multiple regression that enables to simultaneously estimate a series of hypothesized relationships among observed and unobserved (latent) variables to determine whether these associations are consistent with an obtained sample of data [36,37]. The unique advantage of SEM is that by using latent variables, the measurement error can be eliminated. Extracting measurement error in SEM implies greater theoretical meaningfulness and cross-population stability to the parameters than might be achieved with methods such as regression or analysis of variance that do not correct for unreliability [38]. Additionally, SEM allows analysing simultaneously a system of equations that represent (full) theoretical models [36]. SEM also enables to examine relations between variables, such as mediators and moderators, in a simultaneous way (by means of multigroup analysis) that many other techniques cannot [37].

Correlation coefficients were first calculated between the variables of interest. All correlations were below 0.70 , thus multicollinearity was not a concern in the present data [39]. SEM parameters were then estimated and the general fit of the model was assessed first for the total sample and then for the four subgroups based on nutrition knowledge and motivation to change diet. To evaluate the fit of the model, the $\chi^{2}$-value together with degrees of freedom are reported, as well as four other indices: the root mean square error of approximation (RMSEA), the normed fit index (NFI), the nonnormed fit index (NNFI) and the comparative fit index (CFI). Values below 0.08 for RMSEA [40] and above 0.90 for NFI, NNFI and CFI [36] indicate an acceptable fit between the model and the data.

\section{Results and discussion}

\section{Goodness-of-fit of the models}

First in order to analyse the process by which the POP nutrition information achieved its effects on the meal choice and energy intake, a SEM was performed on the total sample. The hypothesized model as presented in Figure 1 performed well for the total sample (Table 2). The $\chi^{2}$ for the model was 172.58 with 74 degrees of freedom $(p<0.001)$. The RMSEA value was 0.078 ; the CFI was 0.96 , the NNFI was 0.94 and the NFI was 0.93 , indicating that the goodness-of-fit indices were satisfactory $[36,40]$. Second, in order to test whether the intervention was more effective in changing the meal choice of subgroups of university canteen customers, a multigroup analysis was performed. The data by subgroup fitted also the model well (but not as good as for the total sample). The $\chi^{2}$ for the model was 439.35 with 320 degrees of freedom $(\mathrm{p}<0.001)$. The RMSEA value was 0.083 ; the CFI was 0.95 , the NNFI was 0.93 and the NFI was 0.83 .

\section{Role of liking}

For the total sample and each of the four investigated subgroups, a significant relation between liking and use of the information was observed (Path A in Table 2). This association was also found to be the strongest, indicating that people who liked the information more, declared to use the information more often. A moderate significant path from liking of the information to a positive effect on attitude or maintenance of high attitudes was observed in the total sample, both directly (Path B) and indirectly (Path $\mathrm{C}$ ) through claimed usage of the information. The direct path from liking to effect on attitude was also found in the subgroup with low knowledge and high motivation (Path B).

Compared to the understanding of the information, liking was a more important predictor of information use. This finding highlights the need for communication efforts and research to move beyond a focus on "understanding of nutrition information" and to emphasize more the liking and attractiveness of information formats. It seems that most consumers have a reasonable understanding of nutrition information when prompted, but only a minority seems to look for nutrition information when shopping [33]. The present study confirmed the general good level of objective understanding of POP nutrition information with less than $10 \%$ of the sample having a score of below 7 on 14. Liking of the information was more heterogeneous among the sample with $25 \%$ having a score of less than 4 on a 7 -point scale. These findings suggest that information characteristics (e.g. display size, colour scheme), which are key determinants of consumers' attention to nutrition information [41] and liking of the information [42], may offer a window of opportunity to improve the effectiveness of nutrition information in terms of targeted dietary change.

\section{Nutrition knowledge versus motivation}

Participants needed both to like and (objectively) understand the information to use it (Path A; Path D), leading to a decrease in energy intake or maintenance of the recommended energy intake level (Path E), as shown in the subgroup of high motivated and knowledgeable consumers. Objective knowledge has also previously been reported to act as a moderator of the relation between objective understanding and use of the information on one hand [33], and between use and effect on energy 


\begin{tabular}{|c|c|c|c|c|c|}
\hline Construct & Path & Construct & $\begin{array}{l}\text { People with low } \\
\text { knowledge and } \\
\text { high intention } \\
(n=70)\end{array}$ & $\begin{array}{l}\text { People with high } \\
\text { knowledge and } \\
\text { high intention } \\
(n=44)\end{array}$ & $\begin{array}{l}\text { Total sample } \\
(\mathrm{n}=220)^{\mathrm{b}}\end{array}$ \\
\hline Liking of information & $\rightarrow^{A}$ & Use of information & 0.58 & 0.90 & 0.59 \\
\hline Liking of information & $\rightarrow^{B}$ & Effect on attitude & 0.31 & & 0.29 \\
\hline Use of information & $\rightarrow^{c}$ & Effect on attitude & & & 0.19 \\
\hline Objective understanding of information & $\rightarrow^{D}$ & Use of information & & 0.38 & \\
\hline Use of information & $\rightarrow^{E}$ & Effect on energy intake & & 0.46 & \\
\hline Subjective understanding of information & $\rightarrow^{F}$ & Use of information & & -0.27 & \\
\hline Objective understanding of information & $\rightarrow^{G}$ & Subjective understanding of information & 0.28 & & 0.20 \\
\hline Subjective understanding of information & $\rightarrow^{H}$ & Effect on energy intake & & & -0.18 \\
\hline Subjective understanding of information & $\rightarrow$ & Effect on subjective knowledge & & & 0.17 \\
\hline Use of information & $\rightarrow$ & Effect on subjective knowledge & & & 0.24 \\
\hline Effect on attitude & $\rightarrow^{k}$ & Effect on energy intake & & 0.41 & \\
\hline
\end{tabular}

${ }^{a}$ Only paths with at least one significant coefficient in any of the three models are included.

${ }^{b}$ Four individuals were removed from the sample because of incomplete information, leaving a final sample of 220 valid cases.

intake on the other hand [15]. Compared to this subgroup, the remainder of the total sample reported a significantly lower objective nutrition knowledge $(\mathrm{p}<0.001)$. Although simplified nutrition information does not require detailed nutrition knowledge [25]; some level of knowledge seems necessary to result in effective usage of the information [12]. Moreover, higher nutrition knowledge may also indicate a higher interest in nutrition and healthy eating [43]. These findings suggest the need for more nutrition education.

A more important moderator of participants' responses to nutrition information was their motivation to change diet as illustrated by the outcome of the multigroup analysis, which was also consistent with previous studies $[44,45]$. In addition to nutrition education, the challenge is to investigate how to motivate people (more) to change dietary habits.

\section{Objective versus subjective understanding of the posted information}

The distinction between objective and subjective understanding was first made by Grunert \& Wills [23], but no study thus far analyzed the importance of subjective understanding in explaining consumers' use of nutrition information. In this study, no significant association was found between subjective understanding and the use of the information, except for the subgroup with high knowledge and high motivation, for whom the relation was negative (Path F). A possible explanation was that the more knowledgeable participants were, the more they tended to underestimate their own performance compared with that of peers [46]. In the total sample and in the subgroup of participants with low knowledge and high motivation, a significant association between objective and subjective understanding was observed (Path G).

Moreover, for the total sample, subjective understanding was negatively associated with an effect on energy intake (Path $\mathrm{H}$ ), but positively with an effect on subjective knowledge (Path I). This could indicate that an important segment of our sample was in a learning stage - hence, not (yet) ready for action - which is comparable to the motivational phase as defined by Renner and Schwarzer [47] and the contemplation or preparation stage of change described by Prochaska \& Velicer [48]. Our results suggest this learning path, but formal confirmation needs further investigation. Simultaneously, the same relations between subjective understanding and effect on energy intake on one hand and subjective knowledge on the other hand were observed in the subgroups with low motivation (results not shown), which indicated that part of this learning segment may probably never evolve to behavioural change because of a lack of personal motivation. Again the importance of personal motivation is highlighted.

\section{Intervention effect on subjective knowledge}

An increase in subjective knowledge or maintenance of high subjective knowledge was found in the total sample to result from a higher use of the information (Path J), but not because of a higher objective understanding of the information. Subjective knowledge is usually defined as people's subjective perceptions of what or how much they know about a specific product compared with peers $[49,50]$. In the present study, we did not measure the perceived knowledge of products but of skills (i.e. to 
evaluate the nutritional value and healthfulness of a food), which is often referred to as self-efficacy [51]. Previous studies have indicated that although nutrition information may not have an immediate effect on food choices and dietary intake, such information may act together with other factors to enhance consumers' selfefficacy and thereby increase the likelihood of healthier food choices being made later on [10,52]. Therefore, a nutrition-information intervention that targets selfefficacy may, in the long run, lead to dietary changes.

\section{Relation between attitude and behaviour}

The results for the subgroup of high motivated and knowledgeable consumers support a positive relation between attitude towards healthy eating and dietary behaviour (Path K) [53,54]. Again this suggests that some baseline level of nutrition knowledge may be necessary to translate a positive attitude into a lower energy intake. In general, the attitude towards healthy canteen meals decreased after posting the information (paired sample's $t$-test $\mathrm{p}<0.001$ ). In both the baseline and follow-up periods healthy meal options or three-star meals constituted a minority of the overall meal offer at the canteens (i.e. about 5\%). A previous study showed that most consumers seem to underestimate the nutritional quality of foods when eating out [6]. Therefore, a possible explanation for the negative change in attitude is the increase in canteen customers' awareness of the actual healthiness of the meals offered after posting the nutrition information. Improving this attitude by increasing the offer of healthy choices might therefore be an important step forward in the development of effective strategies for stimulating healthier meal choices.

\section{Strengths and limitations of the study}

The major strength was the application of a new advanced approach to the evaluation of intervention effects in nutrition research. Another strength of the study was the careful follow-up of the daily food consumption of young adults and its determinants in a real-life setting. Some limitations should also be acknowledged. First, the use of a convenience sample limits the interpretation of the findings to its specific sampling frame. Extrapolation to other populations remains to be further validated. Second, the small sample size did not allow to use the midpoint of 4 to discriminate between participants with a high versus low intention to change their diet. Moreover, the limited sample size may have reduced the ability to detect significant differences in more personal factors with sufficient power. Third, the limited duration of follow-up did not permit evaluations of gradual behavioural changes and persistence of behavioural change over time. Fourth, regarding the hypothetical model, other sequences of hierarchical stages than one from cognitive processing to a behavioural outcome, might have been valuable as well to explain the (in)effectiveness of the nutrition-information intervention. Therefore, further investigation of alternative sequences of hierarchical effects is recommended. A final limitation pertains to the choice of dependent variable where the energy intake from the canteen meal was used as a proxy for the star rating of the reported meal choice, which implies that the analyses do not directly map onto the failed intervention. For example, an individual may have intentions to increase his/her vegetable intake as a result of the intervention but this may not necessarily affect his/her energy intake from the meal. However, from all targeted nutrients/food group in the intervention (i.e. energy, saturated fat, salt and vegetable portion), the energy content had the highest discriminative power for the healthfulness of a meal choice [9]. The main argument for not using meal choice as outcome measure, is that in that case the variance in the dependent variable would have been substantially reduced due to the conversion of an ordinal variable (i.e. star rating of a meal) into a categorical variable, resulting in a considerable loss of information.

\section{Conclusions}

The proposed moderated mediation model of nutritioninformation effects contributed to a better understanding of the ineffectiveness of a nutrition-information intervention in university canteens. The model highlighted the importance of liking of the posted information. The nutrition information was more effective for the more motivated students and for those with a greater objective nutrition knowledge. Increasing students' motivation to change their diet and, to a lesser extent, their knowledge is recommended. Additionally, creating an eating environment with more healthy choices and attractive POP nutrition information complemented with the provision of nutrition education, is proposed for the development and implementation of effective nutrition-information strategies.

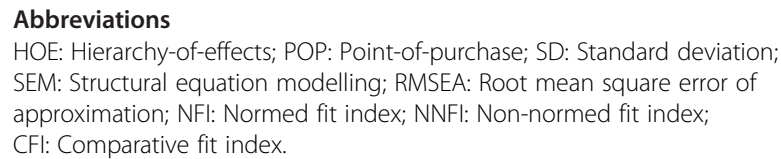

Competing interests

The authors declare that they have no competing interests.

Authors' contributions

$\mathrm{CH}$ conducted the data collection and processing. Furthermore, $\mathrm{CH}$ interpreted the data and drafted the manuscript. ZP performed the statistical analyses and participated in the data interpretation and drafting of the manuscript. WV and JVC revised the manuscript for important intellectual content. All authors contributed to the conceptualization and design of the study. All authors read and approved the final manuscript. 


\section{Acknowledgements}

The authors gratefully acknowledge Prof. dr. Patrick Kolsteren and Carl Lachat for their contributions to the design of the intervention study. They also would like to thank Mr Paul Speeckaert and Mr Philiep Denis, the canteen staff of the Faculty of Bioscience Engineering and the Faculty of Psychology and Educational Sciences for their cooperation during the data collection. The authors would also like to thank the BOF (Bijzonder Onderzoeksfonds Universiteit Gent, Research Fund Ghent University) for its financial support.

Received: 13 October 2011 Accepted: 4 September 2012 Published: 11 September 2012

\section{References}

1. Brunt AR, Rhee YS: Obesity and lifestyle in US college students related to living arrangemeents. Appetite 2008, 51:615-621.

2. Levitsky DA, Halbmaier CA, Mrdjenovic G: The freshman weight gain: a model for the study of the epidemic of obesity. Int J Obes (Lond) 2004 28:1435-1442.

3. Nelson MC, Story M, Larson NI, Neumark-Sztainer D, Lytle LA: Emerging adulthood and college-aged youth: an overlooked age for weightrelated behavior change. Obesity (Silver Spring) 2008, 16:2205-2211.

4. Winkleby MA, Cubbin C: Changing patterns in health behaviors and risk factors related to chronic diseases, 1990-2000. Am J Health Promot 2004 19:19-27.

5. CMM UGent: Rapport enquête studentenrestaurants Universiteit Gent [Report survey student restaurants Ghent University]. Ghent: Committee Marketing and Menu of the student restaurant of Ghent University; 2009.

6. Burton S, Creyer EH, Kees J, Huggins K: Attacking the obesity epidemic: The potential health benefits of providing nutrition information in restaurants. Am J Public Health 2006, 96:1669-1675.

7. Kjollesdal MR, Holmboe-Ottesen G, Wandel M: Frequent use of staff canteens is associated with unhealthy dietary habits and obesity in a Norwegian adult population. Publ Health Nutr 2011, 14:133-141.

8. Lachat CK, Huybregts LF, Roberfroid DA, Van Camp J, Remaut-De Winter AME, Debruyne P, Kolsteren PW: Nutritional profile of foods offered and consumed in a Belgian university canteen. Publ Health Nutr 2009, 12:122-128.

9. Hoefkens C, Lachat C, Kolsteren P, Van Camp J, Verbeke W: Posting pointof-purchase nutrition information in university canteens does not influence meal choice and nutrient intake. Am J Clin Nutr 2011, 94:562-570.

10. Holdsworth M, Haslam C: A review of point-of-choice nutrition labelling schemes in the workplace, public eating places and universities. J Hum Nutr Diet 1998, 11:423-445.

11. Lavidge RJ, Steiner GA: A model for predictive measurements of advertising effectiveness. J Mark 1961, 25:59-62.

12. Verbeke W: Impact of communication on consumers' food choices. Proc Nutr Soc 2008, 67:281-288.

13. Engel JF, Kollat DT, Blackwell RD: Consumer behavior. New York: Holt, Rinehart \& Winston; 1968.

14. Blackwell RD, Miniard PW, Engel JF: Consumer behavior. Ohio: South-Western College Pub; 2005

15. Drichoutis AC, Lazaridis $P$, Nayga RM: Consumers' use of nutrition labels: a review of research studies and issues. Acad Mark Sci Rev 2006, 9:1-22.

16. Moorman C, Matulich E: A model of consumers preventive health behaviors - the role of health motivation and health ability. $J$ Consum Res 1993, 20:208-228.

17. MacKinnon DP, Fairchild AJ, Fritz MS: Mediation analysis. Annu Rev Psychol 2007, 58:593-614

18. Kristal AR, Glanz K, Tilley BC, Li SH: Mediating factors in dietary change: Understanding the impact of a worksite nutrition intervention. Health Educ Behav 2000, 27:112-125.

19. Lockwood CM, DeFrancesco CA, Elliot DL, Beresford SAA, Toobert DJ: Mediation analyses: Applications in nutrition research and reading the literature. J Am Diet Assoc 2010, 110:753-762.

20. Belgian Health Council: Voedingsaanbevelingen voor Belgie: Herziene versie [Dietary guidelines for Belgium: Revised version]. Brussels: Belgian Health Council; 2009.

21. Belgian National Food and Health Plan: Mandate project: Food product references to the Belgian National Food and Health Plan (NFHP) nutritional objectives (Final version). Brussels: Belgian National Food and Health Plan; 2007.

22. Independent Scientific Committee My Choice: Productcriteria Ik Kies Bewust (Versie 3.3) [Nutrition criteria My Choice (Version 3.3)]. Brussels: Independent Scientific Committee My Choice; 2008

23. Grunert KG, Wills J: A review of European research on consumer response to nutrition information on food labels. J Publ Health 2007, 15:385-399.

24. Almanza BA, Hsieh HMY: Consumer preferences among nutrition labeling formats in a restaurant. J Am Diet Assoc 1995, 95:83-85.

25. Feunekes GI, Gortemaker IA, Willems AA, Lion R, Van den Kommer M: Frontof-pack nutrition labelling: Testing effectiveness of different nutrition labelling formats front-of-pack in four European countries. Appetite 2008, 50:57-70.

26. Obayashi S, Bianchi LJ, Song WO: Reliability and validity of nutrition knowledge, social-psychological factors, and food label use scales from the 1995 Diet and Health Knowledge Survey. J Nutr Educ Behav 2003, 35:83-92.

27. Fitzgerald N, Damio G, Segura-Perez S, Perez-Escamilla R: Nutrition knowledge, food label use, and food intake patterns among Latinas with and without type 2 diabetes. J Am Diet Assoc 2008, 108:960-967.

28. Pieniak Z, Verbeke W, Scholderer J: Health-related beliefs and consumer knowledge as determinants of fish consumption. J Hum Nutr Diet 2010, 23:480-488.

29. Acharya RN, Patterson PM, Hill EP, Schmitz TG, Bohm E: An evaluation of the "TrEAT Yourself Well" restaurant nutrition campaign. Health Educ Behav 2006, 33:309-324.

30. Anderson JC, Gerbing DW: Structural equation modeling in practice a review and recommended 2-step approach. Psychol Bull 1988, 103:411-423.

31. Baumgartner $\mathrm{H}$, Homburg $\mathrm{C}$ : Applications of structural equation modeling in marketing and consumer research: A review. Int J Res Mark 1996, 13:139-161.

32. Bergkvist $L$, Rossiter JR: The predictive validity of multiple-item versus single-item measures of the same constructs. J Market Res 2007, 44:175-184.

33. Grunert KG, Fernandez Celemin L, Wills J, Storcksdieck genannt Bonsmann S, Nureeva L: Use and understanding of nutrition information on food labels in six European countries. J Publ Health 2010, 18:261-277.

34. Ajzen I: Constructing a TPB questionnaire: conceptual and methodological considerations. http://socgeo.ruhosting.nl/html/files/spatbeh/tpb. measurement.pdf.

35. Jöreskog KG, Sörbom D: LISREL 7: A guide to the program and applications, Chicago: IL SPSS Inc.; 1989

36. Bollen KA: Structural equations with latent variables. New York: Wiley; 1989.

37. Hair J, Black W, Babin B, Anderson R, Tatham R: Multivariate data analysis. New Jersey: Pearson Education, Inc.; 2006

38. Stephenson MT, Holbert RL, Zimmerman RS: On the use of structural equation modeling in health communication research. Health Commun 2006, 20:159-167.

39. Tabachnick BG, Fidell LS: Using Multivariate Statistics. 4th edition. Massachusetts: Allyn \& Bacon; 2001.

40. Browne M, Cudeck R, Bollen K, Long J: Testing structural equation models. Alternative ways of assessing model fit. Newbury Park: CA: Sage; 1993:136-162.

41. Bialkova $\mathrm{S}$, van Trijp $\mathrm{H}$ : What determines consumer attention to nutrition labels? Food Qual Prefer 2010, 21:1042-1051

42. Berning JP, Chouinard HH, Manning KC, McCluskey JJ, Sprott DE: Identifying consumer preferences for nutrition information on grocery store shelf labels. Food Policy 2010, 35:429-436.

43. Worsley A: Nutrition knowledge and food consumption: can nutrition knowledge change food behaviour? Asia Pac J Clin Nutr 2002, 11:S579-S585.

44. Keller SB, Landry M, Olson J, Velliquette AM, Burton S, Andrews JC: The effects of nutrition package claims, nutrition facts panels, and motivation to process nutrition information on consumer product evaluations. J Publ Pol Market 1997, 16:256-269.

45. Moorman C: The effects of stimulus and consumer characteristics on the utilization of nutrition information. J Consum Res 1990, 17:362-374

46. Battistelli P, Cadamuro A, Farneti A, Versari A: Do university students know how they perform? Int Electr J Elem Educ 2009, 2:180-198. 
47. Renner B, Schwarzer R: Social-cognitive factors in health behavior change. In Social psychological foundations of health and illness. Edited by Suls J, Wallston KA. Oxford: Blackwell; 2003.

48. Prochaska JO, Velicer WF: The transtheoretical model of health behavior change. Am J Health Promot 1997, 12:38-48.

49. Park CW, Mothersbaugh DL, Feick L: Consumer Knowledge Assessment. J Consum Res 1994, 21:71-82.

50. Selnes F, Gronhaug K: Subjective and objective measures of product knowledge contrasted. Adv Consum Res 1986, 13:67-71.

51. Bandura A: Social foundation of thought and action: a social cognitive theory. New Jersey: Prentice Hall; 1986.

52. Contento IR, Randell JS, Basch CE: Review and analysis of evaluation measures used in nutrition education intervention research. J Nutr Educ Behav 2002, 34:2-25

53. Hearty AP, McCarthy SN, Kearney JM, Gibney MJ: Relationship between attitudes towards healthy eating and dietary behaviour, lifestyle and demographic factors in a representative sample of Irish adults. Appetite 2007, 48:1-11.

54. Petrovici DA, Ritson C: Factors influencing consumer dietary health preventativebehaviours. BMC Publ Health 2006, 6:222.

doi:10.1186/1479-5868-9-111

Cite this article as: Hoefkens et al.: Explaining the effects of a pointof-purchase nutrition-information intervention in university canteens: a structural equation modelling analysis. International Journal of Behavioral Nutrition and Physical Activity 2012 9:111.

\section{Submit your next manuscript to BioMed Central and take full advantage of:}

- Convenient online submission

- Thorough peer review

- No space constraints or color figure charges

- Immediate publication on acceptance

- Inclusion in PubMed, CAS, Scopus and Google Scholar

- Research which is freely available for redistribution 